\title{
UM ESTUDO SOBRE A VIOLÊNCIA EM DUAS HISTÓRIAS GRÁFICAS
}

\author{
A STUDY ABOUT THE VIOLENCE IN TWO GRAPHIC STORIES
}

Leconte de Lisle Coelho Junior*

Coelho LL. Um estudo sobre a violência em duas histórias gráficas. Rev Bras Cresc Desenv Hum 2005; 15(02):55-68.

\begin{abstract}
Resumo: As histórias gráficas, também conhecidas como histórias em quadrinhos, são uma das formas mais antigas de expressão da humanidade. Elas refletem os valores da sociedade e podem servir como uma forma de educação. Esse estudo buscou reconhecer descritores da violência estilizada sob a forma de imagens agressivas e a intencionalidade de se cometer algum ato violento nas personagens de Fushigi Yûgi e Yu Yu Hakushô, que são histórias gráficas de origem japonesa denominadas 'mangás'. A análise estatística descritiva unida à análise semiológica permitiu reconhecer os principais componentes, acima apontados, das histórias. Verificou-se que estes recursos visuais contêm violência não somente explícita, mas também intencional, sendo a primeira forma a mais difundida, e que as personagens do gênero masculino são mais violentas que as de gênero feminino. Conclui-se também que estas histórias não podem ser tidas como as únicas e mais perigosas fontes de violência na sociedade.
\end{abstract}

Palavras-chaves: Histórias gráficas. Mangás. Violência.

\section{INTRODUÇ̃̃O}

As histórias gráficas são, segundo Cir$\mathrm{ne}^{1}$, mais do que uma simples forma de comunicação: são uma espécie de exposição dos sentimentos humanos e uma criação que pode refletir a realidade não somente do autor como da sociedade na qual o mesmo está inserido.

As histórias gráficas, embora camufladas por idealização ou sob o domínio do mundo da imaginação, podem revelar conteúdos da realidade humana. No que concerne ao presente estudo, não importa a profundidade dos cenários fantasiosos nem se uma ou outra obra tem mais tópicos apoiados na instância imaginária. Interessa a relevância que estes conteúdos adquirem enquanto sentido para quem os consome, ou seja, como objetos de consumo em uma sociedade pós-moderna onde impera a necessidade do 'ter'.

A escolha do termo 'história gráfica' é utilizado em detrimento do mais usualmente conhecido 'histórias em quadrinhos' pois este último denota uma idéia de infantilização mas, conforme pode ser visto em $\mathrm{Franco}^{2}$, as histórias gráficas nada têm de infantil, embora muitas se destinem a este público. Elaborar uma obra dessas liga-se ao conhecimento de inúmeras técnicas, assim como implica em entender bem o tema escolhido e saber identificar o público alvo para que a obra não seja um fracasso financeiro.

As histórias gráficas possuem, para cada sociedade, um nome próprio, recebendo a denominação de comics nos Estados Unidos, bande dessinée na França e Bélgica, bandas

\footnotetext{
Doutorando em Psicologia pela Universidade Federal do Espírito Santo. Endereço: Rua Carlos Delgado Guerra Pinto, n² 265, ap.211. Jardim Camburi. Cep.:29090-040. VitórialEs. E-mail: lecontey @ yahoo.com.br
} 
desenhadas em Portugal, fumetti na Itália, historieta na Argentina e nos outros países latinoamericanos, TBO na Espanha e gibi ou histórias em quadrinhos no Brasil; no Japão são chamadas de mangá. ${ }^{2}$

Especificamente os mangás têm sido conceitualizados como:

"Traços simples e expressão exagerada são elementos dos mangás, e o acréscimo da impressão de movimento cria uma forma de comunicação ainda mais expressiva" ${ }_{3}$ (p.12).

Ou ainda:

"O mangá tem linguagem e característica próprias, bem diferentes das ' $H Q$ 's americanas ou européias. Eles são, normalmente, desenhados a nanquim e publicados em preto e branco. O traço dos personagens é muito estilizado e, em muitos casos, os olhos são maiores que o normal para que as emoções como raiva ou espanto sejam passadas com a maior realidade possivel. Outra diferença é a leitura. Os orientais têm o hábito de ler da direita para a esquerda, exatamente ao contrário do que nós fazemos no ocidente. Isso, no entanto, não impediu que a 'febre' ultrapassasse as fronteiras nipônicas e invadissem os Estados Unidos, a Europa, a Indonésia, a Tailândia, o México e agora, finalmente, o Brasil". ${ }^{4}$

Assim, os mangás seriam histórias gráficas que teriam suas próprias características e por isto estariam se espalhando de forma maciça em vários países ao redor do mundo. Segundo $\mathrm{Bosi}^{5}$, esta é uma das principais marcas da cultura de massas: o super-desenvolvimento das produções artísticas e seu refinamento para o melhor consumo. O consumo se liga ao lucro que aumenta a produção, ou melhor, a reprodução do objeto inicial.

No caso da Cultura Pop Japonesa, cujo núcleo são os mangás, os animês (desenhos animados), as animesongs (trilhas sonoras de desenhos animados), a adoração aos 'Pop idols' (ídolos do 'Mundo Pop') e os games (jogados ou não 'On-line') esta massificação se faz presente $^{6}$. Para ocorrer uma estabilidade nas vendas e lucros, muitas vezes se apela para temas picantes, como a temática sexual (por exemplo, 'Love Junkies' da Editora JBC e Ranma 1/2 daEditora Animangá), violenta (Dragon Ball da Editora Conrad) ou ficcional (Dark Angel da Editora Paninni), embora outros levem em conta os aspectos do cotidiano, da história e da cultura própria a um país ${ }^{7}$.

No presente estudo, o tema escolhido foi o da violência, lembrado geralmente como um estigma dessas produções japonesas ${ }^{8}$. A violência9 ${ }^{9}$ seria:

“(...) vários elementos, incluindo a intenção de causar dano, a natureza física do dano e o envolvimento dos seres animados. Mais precisamente, a violência é definida como qualquer representação pública de uma ameaça crivel de força física ou o uso real de tal força a fim de machucar fisicamente um ser ou grupo de seres animados. A violência também inclui certas representações de conseqüências fisicamente prejudiciais a um ser ou grupo de seres animados, que se dá como um resultado de um meio violento invisivel." (p.79).

Nascimento e Melo ${ }^{8}$ entendem que a violência está impregnada nos mangás e outros produtos pop's japoneses e, segundo Wilson e colaboradores ${ }^{9}$, a violência pode ser explícita e simbólica, a primeira quando o ato é exposto e a segunda quando há intenção de dolo. Assim, este estudo tem como objetivo verificar a frequiência da violência nos mangás Fushigi Yûgi (Editora Conrad) e Yu Yu Hakushô (Editora JBC), seja de forma explícita (condutas) ou simbólicas (verbalizações e intenções) das personagens.

Estes mangás foram escolhidos porque o primeiro foi um dos grandes sucessos no Japão e o maior lucro de publicação do gênero nos Estados Unidos na ultima década e meia. Já Yu 
Yu Hakushô é o maior recorde editorial na área de mangás, tendo chegado a 2 milhões de cópias vendidas ${ }^{4}$. A seguir, exporemos algumas explanações acerca destas fontes de arte a fim de que se entenda melhor as mensagens por eles emitidas ao seu público.

\section{Sobre as Histórias Gráficas: Os Mangás}

Segundo alguns autores ${ }^{2,10,11}$, as histórias gráficas surgem com as pinturas rupestres nas cavernas européias e asiáticas. São vestígios de que os antigos moradores daqueles lugares não somente demarcavam seu território, como também contavam com simbolismos as estórias de suas tribos, seus rituais religiosos, caçadas e até os combates com outros clãs. Seu uso se desenvolve com as pinturas nas paredes das pirâmides egípcias e nas vilas greco-romanas, aparecendo também como tapeçarias medievais.

No ocidente, segundo Alves ${ }^{10}$, por volta do século XVII, com os livros de literatura infantil de Perrault sendo ornados por gravuras, fica mais disseminada a leitura junto com desenhos. Mas, somente em 1837, surgirá realmente a primeira história gráfica no formato que se conhece hoje: "Les Amours de Monsieur VieuxBois", do suíço Rodolphe Topffer (1799-1846). Pouco tempo depois, surgem as tiras dominicais publicadas em jornais norte-americanos de qualidade inferior, focalizando o público adulto. Tem-se então uma significativa diferença no Ocidente quanto à origem e ao interesse. Se no 'velho mundo', as historietas aparecem como álbuns, na América elas surgem vinculadas à editoração de jornais, donde o material ser considerado de qualidade inferior. Nos Estados Unidos, elas são inicialmente voltadas aos adultos, 'eram coisa de gente grande', bem diferente do que se passou a pensar de ser direcionado às crianças.

No Brasil, a primeira revista surge em 1905 com o título de Tico-Tico e, segundo Alves $^{10}$, era destinada ao público infantil. Também era usada como forma de ensinar às crianças aspectos da geografia, história e folclore brasileiros. Aúnica grande publicação nacional posterior é a "A Turma da Mônica", de Maurício de Souza na década de 1960, que vai se manter estável até os dias de hoje, passando a sofrer a sistemática concorrência dos comics (principalmente de 'Walt Disney') e depois dos Mangás.

Os mangás estão historicamente ligados ao desenvolvimento artístico do Japão. No Período Kamakura, por volta do século XII d.c, ocorreu a popularidade da pintura de retratos e conforme Tazawa, Matsubara, Okuda e Nagahata $^{12}$ :

"O Shogunato Kamakura era baseado em laços de lealdade mútua existentes entre senhores e vassalos. Em contraste à rígida e tradicional estratificação e subordinação de classe, a gente estava desenvolvendo, cada vez mais, uma consciência de ser humano, $e$, concomitantemente, havia mais preocupação e interesse pelo seu semelhante." (p.59-60).

Daí se desenvolveu uma prática de desenhar não somente retratos de pessoas, mas suas biografias. Isto ocorria em rolos de papel, onde a história de vida da pessoa era narrada na medida em que eram desenrolados; são os chamados ' $\hat{\text { E-Kimono' }}{ }^{13}$. Em 1681, um pintor chamado Hishikawa Moronobu passa a retratar os costumes de vida das pessoas de classe mais humilde, como artesãos e pescadores, vendendo suas obras a preços módicos, o que vai popularizar a arte do desenho. É o início dos 'Ukiyo-Ê', ou seja, 'desenhos populares' cujos temas eram sobre bairros movimentados e alegres, teatros e as tradicionais lutas de Sumô que serão produzidos em massa e que vai se espalhar por todo o país ${ }^{12}$.

Por volta de 1814, o mais famoso artista do estilo Ukiyo-Ê, Katsushika Hokusai (17601849), começa uma série de ilustrações que se chamará de 'Hokusai Mangá', originando o formato atual das histórias gráficas japonesas, 
o mangá3.

Portanto, antes do desenvolvimento das histórias gráficas no ocidente, mais notadamente na Europa ${ }^{10}$, já havia tal costume no Oriente. Na Era Meiji (1868-1912), com a abertura comercial, o Japão teve contato com a cultura ocidental e, por conseguinte, com o estilo comic norte-americano e europeu, o que veio a influenciar decisivamente a arte dos mangakás (desenhistas japoneses), o que mostra a convergência do que seria uma arte própria dos japoneses que se coaduna com o estilo do ocidente ${ }^{14}$.

No Brasil, os mangás surgiram muito provavelmente com a chegada dos primeiros colonos nipônicos desembarcados do Kasato Maru no dia 18 de Junho de 1908, no Estado de São Paulo. Porém, foi no ano de 1962 que surgem os primeiros esforços de se fazer um mangá totalmente nacional ${ }^{6}$, mas que não foram adiante por ser a editora responsável muito pequena e incapaz de competir com os gigantes do ramo. Assim, as figuras de personagens do estilo mangá ficaram restritas a alguns anúncios de revista mas fica a marca histórica de que o Brasil foi o primeiro país a editar mangás fora do Japão.

Cerca de oito (8) décadas após, em meados dos anos de 1980, surgiram os primeiros mangás no mercado de literatura brasileiro, sendo que Akira foi, sem dúvida, um marco deste estilo neste país e em outros. Sua publicação foi tão estrondosa que logo seu homônimo em animê foi importado e também se tornou um sucesso: "Akira, um dos mangás japoneses de maior sucesso, resultou em um longa metragem animado que tornou-se cult, tendo recentemente passado por uma remasterização e sido relançado em cinemas da Europa e Estados Unidos"2 (p.147).

A mídia impressa aos poucos se desenvolveu. Levando em consideração o gosto dos leitores, principalmente juvenis, e aproveitando a escalada de consumo dos desenhos animados provenientes do Japão, a década de
1990 foi marcada pela produção dos seguintes títulos: Victory, Holy Avenger, Megaman, Ranma 1/2, Cavaleiros do Zodíaco, Card Captors Sakura, Rayearth, Rouroni Kenshin, Vídeo Girl AI (produzidos pelas Editoras nacionais Paninni, Talismã, Animangá, JBC, e Conrad) e muitos outros, com parte dos lucros, sedimentando de vez este estilo no mercado editorial brasileiro. Para se ter uma comparação das diferenças em números, Luyten ${ }^{14}$ confirma que, até o ano de 2002, de tudo o que fora publicado no Japão, 38\% correspondiam à produção de mangás, extrapolando um crescimento de $300 \%$. Evidentemente, são dados do Japão onde existe uma tradição e comprometimentos com a arte, valendo citar a existência da Mangáki-Sagai a maior revistaria de mangás localizada em Tókio, com um acervo de 10.000 títulos. No Brasil, esses números não passam a casa das 100.000 cópias vendidas por mês.

No Japão, os mangás têm uma grande variabilidade, o que cria um mercado de consumo estável, enquanto no Ocidente o consumo de histórias gráficas é tido como infantil ${ }^{11}$. Contudo, os mangás podem ser divididos, de uma maneira geral, em Shonen mangá, Shojo mangá, Jidaimono mangá, Spokon mangá e Hentai mangá como pode ser visto na análise de Moliné ${ }^{11}$ :

-Os Shonen mangá: da palavra japonesa 'shonen' que significa 'garoto'; esses mangás têm como características básicas, muita ação, extremo dinamismo no movimento de todas as personagens, um certo erotismo e violência e, geralmente, dão grande margem de lucro financeiro. Berserk (Editora Paninni), Cavaleiros do Zodíaco (Editora Conrad) e Yu Yu Hakushô (Editora JBC) são exemplos desta categoria;

-Os Shojo mangá: da palavra 'shojo' que do idioma japonês se traduz como 'garota'; ao contrário do anterior, são produtos direcionados ao público feminino. Trazem estórias de 
conteúdo romântico, com geralmente um par de personagens principais que luta para ficarem em uma situação afetiva estável, independente do contexto; é o caso de Fushigi Yûgi (Editora Conrad) como exemplo desta categoria;

-Os Jidaimono mangá: esta palavra tem um significado próximo à 'coisa histórica', e são os mangás que retratam os eventos verídicos da história japonesa, desde o período em que a nobreza governava absoluta até a submissão ao xogunato, ou a abertura político-comercial na Era Meiji; um item deste ramo seria Lobo Solitário (Editora Paninni);

-Os Spokon mangá: 'spokon' deriva da corruptela da palavra inglesa 'sports', isto é, mangás que têm como fundo, estórias de superação e competitividade no mundo dos esportes. No Brasil este tipo de produto é representado por Slam Dunk (Editora Conrad); e finalmente,

-Os Hentai mangá: esta palavra significa 'depravado', 'perverso', e designa mangás de cunho pornográfico que fazem bastante sucesso em uma sociedade tão rígida como é a japonesa. No Brasil, o único título, atualmente, que pode ter este rótulo seria Love Junkies (Editora JBC).

Apesar destas subdivisões, não muito estritas, há também aqueles que comporiam as categorias de 'ficção-científica', 'medieval', 'comédia estudantil', 'militar', 'policial', 'terror', entre tantos outros, sendo que o que chega ao mercado brasileiro é ainda uma pequena parte de um 'grande todo'.

No Brasil, o primeiro mangá nacional que fez sucesso e garantiu seu espaço para uma reedição foi Holy Avenger (Editora Talismã), editada entre os anos de 2000 e 2003 . Podese classificar este produto como do tipo de estórias medievais, havendo grandes dificuldades de publicação ${ }^{15}$. Esta produção impressa seguiu rigorosamente o estilo japonês, inclusive a disposição dos traços não-orientais das personagens.
Conforme Franco ${ }^{2}$, a editoração de uma história gráfica tem que levar em conta alguns suportes técnicos que vão ambientalizar e facilitar a compreensão do que se passa ao leitor. Corresponderiam a uma regra geral, denominada por este autor de 'Elementos de Linguagem', de modo aos artistas poderem enquadrar seu público-alvo. É a estrutura de linguagem em comum, junto com os traços de desenho que dão sentido às estórias:

1- Percepção Visual Global: seria a gestalt, ou seja, o conjunto de enquadramentos em si que devem dar uma noção do que se passa em uma sequiência (passado, presente e futuro); nos mangás, os enquadres provocam um sentido de dinamismo onde, em vários quadros entrepostos, sem necessariamente aparentar uma seqüência, a estória vai sendo contada;

2- Elipses: São os 'vazios' entre os enquadramentos, o que proporciona a operação cognitivo-simbólica de preenchimento do sentido da ação que ocorre. Por isso alguns autores ${ }^{2,11}$ afirmam que as histórias gráficas são uma 'mídia fria', pois se permite o preenchimento de sentido, pelos leitores, do que está ocorrendo. Um mangá, como a maior parte deste tipo de mídia, estimula um certo esforço para a compreensão de condutas expostas;

3- O Tempo: Para dar uma real percepção temporal são desenhados enquadres menores para dar sentido de pouca quantidade de tempo transcorrido, pois se espera que o leitor demore menos nesses quadros do que nos maiores que, por sua vez, darão a sensação temporal de período mais lento passando;

4- O Enquadramento: Mais popularmente conhecido como 'quadrinho', é uma representação bidimensional da realidade, isto é, demonstra o aspecto espaço-temporal de um determinado ambiente. Os enquadramentos são a essências da narrativa das histórias gráficas e, conforme Franco ${ }^{2}$ "Por tratar-se de uma linguagem icôno-literária, as HQs também mantêm uma certa relação com outras artes como a pin- 
tura, o teatro, a fotografia e a televisão" (p.29). Por isto é comum o pareamento de uma estória de mangá com a sua produção em desenho animado (animê), como foi o caso anteriormente citado de Akira;

5- Balão de Fala: É a técnica primordial de desenvolvimento da comunicação entre personagens deste tipo de mídia: “(...) os balões também podem servir para abrigar onomatopéias e ícones que representam atitudes das personagens, são metáforas visuais que funcionam como convenções lingüísticas dos quadrinhos"² (p.48). Aqui está a base da interlocução gráfica;

6- Onomatopéias: Pode ser conceitualizado como sendo a representação gráfica dos sons. Na produção de mangás é de extrema importância pois dá liberdade ao autor para expressar não somente a situação em que se encontra a personagem mas também um sentimento:

"A língua japonesa possui uma tradição antiga de usar muitas onomatopéias na fala. No mangá, para dar clima à cena e compensar a ausência de sons, a variedade cresce a níveis estratosféricos. Na tradução, é preciso inventar um grande número de onomatopéias para compensar essa diferença. Além disso, no Japão existem onomatopéias que servem apenas para descrever a situação, como, por exemplo uma onomatopéia para representar ausência de som e outra para indicar uma pessoa ficando vermelha de vergonha"16 (p.90).

Portanto, sem o recurso da onomatopéia para enriquecer a leitura de um mangá, o mesmo corre o risco de perder o sentido, além de interferir no modelo original da arte. Quanto mais se utiliza, mais diversificado e interessante, estimulando a atenção de quem lê.

7- Linhas de Movimento: É um recurso para dar a entender ao leitor que ocorre um movimento. São chamadas também de "linhas cinéticas' ${ }^{2}$. Nos mangás, geralmente se dá a impressão que o fundo da figura (gestalt) é que está em movimento, aumentando a idéia de movimentação no contexto;

Com este conjunto de noções de técnicas da arte, compreende-se melhor como ocorre a elaboração dos mangás. Sendo, de certa maneira, gerais, isso facilita ao leitor nacional se adaptar à leitura deste novo estilo.

Por outro lado, como no Brasil há uma colônia nipônica muito grande que, conforme Bolognini e Payer ${ }^{17}$ chega a 1,3 milhões de pessoas, os costumes se mesclaram e acomodações de hábitos se formaram. Por exemplo, nos Estados Unidos, a venda do título Fushigi Yûgi foi responsável pela maior parte dos US\$ 100.000.000 de lucros que só os shojo mangá arrecadaram no ano de 2002, sabendo-se da anterior re-edição do mesmo no Japão ${ }^{18}$. Este tipo de conexão pode manter um imenso corpo de consumidores.

Embora no Brasil o acúmulo de capital seja menor e o consumo também, parece haver um crescimento gradual neste setor ${ }^{6}$. Tanto Fushigi Yûgi quanto Yu Yu Hakushô foram os 'carros-chefe' dessa evolução.

Afirma Moliné ${ }^{11}$ que o significado de Fushigi Yûgi é "O Jogo Misterioso", tendo sido desenhado por uma novata no mundo dos mangás chamada Yû Watase, no ano de 1992. Misturando o formato tradicional de shojo mangá a conteúdos de comédia e mitologia chinesa, a obra foi finalizada em 1996, obtendo um dos maiores lucros da área gráfica, repetindo o mesmo nos Estados Unidos em 2002. Segue-se a estória que:

"Tem início quando Miaka Yûki, uma atraente e pouco brilhante estudante de 15 anos, está na biblioteca lendo um livro juntamente com sua amiga, a mais aplicada Yui Hongô. De uma hora para outra, as duas são transportadas a um mundo paralelo, com um ambiente similar ao da China medieval (...)".(p.100-1).

Essa história gráfica originou uma série de 52 capítulos de animês, com o mesmo su- 
cesso anterior. O outro objeto de estudo, $\mathrm{Yu} \mathrm{Yu}$ Hakushô, significa "Brincando com Espíritos" $"$, tendo sido produzido em 1990 por Yoshihiro Togashi, recebendo de Moliné ${ }^{11}$ a classificação de fantástico com conteúdos de terror. O trabalho foi finalizado em 1994, sendo o maior recorde de lucros deste tipo de mídia até hoje no Japão. A produção de animês foi de 112 capítulos e a estória

“(...) tem como protagonista Yusuke Urameshi, um estudante de 14 anos, bastante indisciplinado, mas de bom coração. Um dia, ao salvar a vida de um garoto que estava prestes a ser atropelado, ele morre. Como sua morte não estava prevista, Koenma, filho do Sr. Enma Daioh, decide conceder a Yusuke a chance de ressuscitar (...) uma vez que youkais fugiram do Makai, o mundo dos demônios, e vão para a Terra cometer atos delinqüentes, a missão de Yusuke será capturálos". (p.170-1).

Desta forma, fica caracterizado o aspecto mítico das duas obras; no primeiro o contexto situa-se em uma 'China medieval' e, no segundo, a relação de seres sobrenaturais encarregados, na tradição popular japonesa, de tratar das almas dos mortos (Koenma e Enma Daioh).

A busca da midiatização do mito será também o escopo deste trabalho que terá como procedimento a análise semiológica proposta por Barthes ${ }^{19}$. Por isso, faz-se mister a exposição dos principais conceitos da Análise Semiológica, técnica responsável pela expressão crítica do desmonte dos sentidos expressos nos textos, nas músicas, nas imagens etc. ${ }^{20}$

\section{Linguagem e Análise Semiológica}

A análise semiológica é uma técnica que surge com a nova teoria da linguagem estrutural do suíço Ferdinand de Saussure (1857-1913) no início do século XX. Conforme Penn ${ }^{20}$, tal teoria concebe a linguagem como um sistema, ou seja, uma estrutura que mantém os signos constituidores de uma linguagem 'unidos' e delimitando uma língua. Sendo assim, uma língua seria também reconhecida como uma estrutura, que se funda na subjetividade de um determinado grupo social e que pode, por conseguinte, fazer aflorar as normas das relações entre as pessoas.

Essas normas recebem o nome de signos que, por sua vez, são formados por significantes (imagem) e significado (conceito) ${ }^{21}$. Quando alguém possui uma idéia acerca de algum objeto, essa pessoa automaticamente forma uma imagem que está acoplada a um conceito; assim, o indivíduo tem condição de transitar no meio social, pois que teria condição de saber como agir perante tal objeto (normas). São estas regras (signos) que permitem que os membros de um mesmo grupo entendam o que se diz, por exemplo, numa discussão ou quando uma mensagem de uma revista ou livro é compreendida $^{21}$.

A linguagem basicamente vai se constituir quando alguns termos forem escolhidos em detrimento de outros e na forma de que ordem sejam escolhidos e combinados com outros tantos. Esta combinação chama-se relação sintagmática ou apenas sintagma. Por exemplo, no período: "A capa da revista é amarela”, está marcada por algum motivo por estes signos, e não por outros, e traduz uma seqüência de termos ('capa', 'revista', etc.). Isto sem esquecer que a seqüência somente poderia ser aceita pela estrutura lingüística dominante no grupo social. Por exemplo: "Amarela a revista é capa da", não teria serventia num grupo social brasileiro, visto que não traz sentido ao leitor.

Desta forma, Penn ${ }^{20}$ sinaliza que Saussure criou a semiologia para que esta servisse de instrumento de pesquisa dos signos no meio social. Afirma esta mesma autora, que Roland Barthes foi o autor que primeiramente melhor utiliza a semiologia na forma de 'Análise Se- 
miológica', ou seja, a utilização da semiologia para desmascarar os significantes e significados construídos nas mensagens. Na medida em que os significantes são variáveis, ambíguas mesmo ${ }^{19}$, eles podem transmutar-se simultaneamente, ao passo que na linguagem se exige um sentido, uma seqüência. $\mathrm{O}$ que vai eliminar esta ambigüidade será a formulação do texto onde a imagem será capturada. Neste momento, a iconografia será definida e a análise semiológica se faz necessária a fim de determinar o real sentido da mensagem. Isto sugere que tal análise venha a ocorrer no nível simbólico.

Diferenciando-se de Saussure, Barthes ${ }^{19,22,23}$, divide o conceito de signo em sistema de primeira ordem, e sistema de segunda ordem. No primeiro, a lógica segue a semiologia saussuriana; para o signo, tem-se o significante e significado. Já no sistema de segunda ordem, o que era signo no sistema anterior, torna-se significante. Isto quer dizer que o signo passa a ser um indutor de significação porque, neste momento, existe algo além do próprio signo que é a significação produzida na cultura. Por isso que quando ele muda de lugar, podese afirma ser este o aspecto psicológico-simbólico dos estudos semióticos, pois existe uma transferência advinda do meio externo que desloca estas significações.

Para finalizar, deve-se a Barthes ${ }^{19}$ a conceitualização de denotação, conotação e mito como sendo níveis de abstração a fim de se interpretar algum dado de significação. No primeiro caso, é necessário ao leitor o conhecimento da língua e da sua cultura para a compreensão do que se transmite. No segundo nível, o conhecimento é estritamente cultural: conjunto de objetos definidores desta. E, finalmente, no terceiro nível tem-se o mito, que é a naturalização de normas e ideologias partilhadas por uma sociedade. Desta maneira afirma Penn ${ }^{20}$ :

"A tarefa do semiólogo é desmistificar, ou 'desmascarar' esse processo de naturali- zação, chamando a atenção para a natureza construída da imagem, por exemplo, identificando os conhecimentos culturais que estão implicitamente referidos pela imagem ou contrastando os signos escolhidos com outros elementos de seus conjuntos paradigmáticos". (p.325).

Geralmente o material de pesquisa que contém imagens trás em seu bojo conteúdos míticos, que servem, como diz Barthes ${ }^{19,22}$, para 'ancorar' a interpretação das pessoas. Ao tentar captar o que a imagem quer dizer, o indivíduo captura a significação, ou melhor, é capturado por ela, visto que a mesma está recheada de uma ideologia que permite esta mesma ancoragem. Em outras palavras, quando o leitor tenta compreender o que a imagem diz, é neste momento interpretativo que a ideologia o cativa, quando o pseudo-entendimento se faz presente.

Face a isso, o presente estudo foi realizado à luz da análise semiológica narrativa para tentar desnaturalizar o que está contido nas histórias gráficas. Vale lembrar que este tipo de pesquisa documental possui precedentes não somente com histórias gráficas ${ }^{1,25}$, mas também com revistas/magazines ${ }^{26}$.

O objetivo deste estudo foi verificar a frequiência da violência nos mangás Yu Yu Hakushô e Fushigi Yûgi, seja de forma explícita (condutas) ou simbólicas (verbalizações e intenções) das personagens. Ele se baseou na construção de duas hipóteses:

Hipótese 1: As personagens de gênero masculino são a fonte de maior freqüência de violência que as personagens de gênero feminino.

Hipótese 2: À cada edição, a frequiência da violência exposta tem um acréscimo, ou seja, aumenta.

\section{MÉTODO}

Foram objeto deste estudo 38 edições da história gráfica Yu Yu Hakushô (totalizando 
cerca de 3800 páginas) e 36 da história gráfica Fushigi Yûgi (totalizando em torno de 3600 páginas). O período da realização da pesquisa foi de fevereiro de 2003 a abril 2005 e contou também com a análise de todos os 17.036 enquadramentos do primeiro título acima citado e dos 14.600 do segundo.

Vários autores discutem as modalidades de pesquisa quantitativa e qualitativa nas ciências humanas e especialmente na ciência psico$\operatorname{logia}^{23,24}$. No caso desta pesquisa, a importância estava em tentar mostrar o que havia por detrás dos enquadramentos. Não haveria possibilidade de se chegar a uma interpretação mais precisa se não houvesse um método que pudesses destituir as imagens de seu lugar aparentemente imobilizado e encontrar um verdadeiro sentido no que elas queriam dizer, e permitisse a análise dos diálogos travados entre os personagens que, conforme Cirne ${ }^{1}$ são igualmente relevantes. Foi utilizado, portanto, um método qualitativo, baseado na análise semiológica que, segundo Vergueiro ${ }^{25}$, já fora utilizado em histórias gráficas.

Procedimento: Foi realizada uma análise semiológica de cada edição das histórias gráficas, baseando-se em Barthes ${ }^{19,22}$, e uma análise descritiva da frequiência dos enquadramentos a fim de identificar a quantidade de violência explícita e simbólica em cada edição, além de tentar identificar a violência e diferença no gênero das mesmas ${ }^{23}$.

\section{RESULTADOS E DISCUSSÃO}

Foi encontrada violência, dos dois tipos, em 24,60\% do total dos enquadramentos no mangá de Yu Yu Hakushô; em Fushigi Yûgi esta porcentagem é de 11,63\%. Portanto, em nenhum dos dois casos a violência chega a ser metade dos enquadramentos. Na tabela 1 , está a distribuição da quantidade de violência exposta no material explorado (17.036 enquadramentos em
Yu Yu Hakushôe 14.600 em Fushigi Yûgi).

Tabela 1: Violência Explícita e Violência Simbólica nos Enquadramentos

\begin{tabular}{c|c|c}
\hline Categorias & Fushigi Yûgi & Yu Yu Hakushô \\
\hline Violência Explícita & $8,93 \%$ & $18,03 \%$ \\
\hline Violência Simbólica & $2,70 \%$ & $6,57 \%$ \\
\hline Total & $11,63 \%$ & $24,60 \%$ \\
\hline
\end{tabular}

Em Fushigi Yûgi, a violência explícita atinge $8,93 \%$ dos enquadramentos desenhados para $2,70 \%$ de violência simbólica. Assim, além de ser uma produção menos violenta, o conteúdo 'negativo ' alcança apenas cerca de um décimo do total. Já em Yu Yu Hakushô, a maior parte da violência também é explícita (18,03\%), enquanto a violência simbólica é $6,57 \%$.

Vale assinalar que somente a partir da edição ${ }^{\circ} 12$ de Yu Yu Hakushô começa a aparecer a tarja de indicação de faixa etária dizendo "Contém cenas de violência. Desaconselhável para menores". Porém, a edição ${ }^{\circ} 10$ foi a mais violenta da série. Na outra obra aqui estudada, a tarja indicativa aparecia em algumas edições, como nas de ns ${ }^{\circ} 3$ e 17 , nos dizeres: “Aconselhável para maiores de 12 anos". Mas na última edição, a de $n^{\circ} 36$, que foi a mais violenta da série, não havia este aviso. A diferença entre o gênero das personagens e a violência exibida pode ser vista na tabela 2 .

Tabela 2- Diferença na violência entre personagens Masculinos e Femininos

\begin{tabular}{c|c|c}
\hline Categorias & $\begin{array}{c}\text { Fushigi } \\
\text { Yûgi }\end{array}$ & $\begin{array}{c}\text { Yu Yu } \\
\text { Hakushô }\end{array}$ \\
\hline $\begin{array}{c}\text { Violência de } \\
\text { Personagem Masculino }\end{array}$ & $9,25 \%$ & $22,72 \%$ \\
\hline $\begin{array}{c}\text { Violência de } \\
\text { Personagem Feminino }\end{array}$ & $2,38 \%$ & $1,88 \%$ \\
\hline Total & $11,63 \%$ & $24,60 \%$ \\
\hline
\end{tabular}

Tentou-se identificar a origem das ações e intenções violentas das estórias e, confor- 
me a tabela 2, a violência oriunda de personagens masculinos foi maior que a dos personagens femininas. Em Yu Yu Hakushô, os homens seriam mais hostis $(22,72 \%)$ contra $9,25 \%$ da outra obra. No referente às mulheres, existe uma pequena diferença de Fushigi Yûgi $(2,38 \%)$ para a outra história gráfica $(1,88 \%)$.

Interessante notar que, em muitas edições de ambas as obras, as personagens femininas não tinham nenhuma ação ou intenção que expressasse violência, inclusive elas eram tão se- cundárias que mal apareciam nas revistas. Talvez isto possa expressar uma cultura onde o homem é visto como protetor e que, por isso, tenha que se expôr mais, correndo mais perigo do que as mulheres.

A análise semiológica permitiu desmascarar os sentidos encobertos; porém, devido à extensão de tempo e espaço para exibir tal análise, será apresentada a análise de cada edição mais violenta dessas obras, no caso de $\mathrm{Yu} \mathrm{Yu}$ Hakushô a de $n^{\circ} 10$ e a de $n^{\circ} 36$ na de Fushigi Yûgi.

Quadro 3 - Relatório de Análise da Edição no 10 de Yu Yu Hakushô

\begin{tabular}{|c|c|c|c|}
\hline Den & Sintagma & Mito & Cultura \\
\hline $\begin{array}{l}\text { 1-Fuga de estudantes: } \\
\text { roupa de colegial comum } \\
\text { no Japão (uniforme de } \\
\text { marinheiro: saia, blusa), } \\
\text { roupa leve: jeans, blusa } \\
\text { sem mangas; cabelos curtos } \\
\text { e lisos, cabelos longos } \\
\text { presos como 'rabo de } \\
\text { cavalo'; postura defensiva, } \\
\text { postura de agressão; } \\
\text { contato físico hostil contra } \\
\text { outros seres humanos, } \\
\text { sangue, luta contra } \\
\text { professores. } \\
\text { 2-Luta entre um ser } \\
\text { humano e um demônio: } \\
\text { briga fantástica, raios; } \\
\text { roupas: uniforme de } \\
\text { colégio, roupa estilo } \\
\text { oriental (árabe); postura: } \\
\text { ofensiva, hostil, lançar } \\
\text { raios dos dedos, de um } \\
\text { cajado, rosto mostra raiva e } \\
\text { cansaço, sangue; } \\
\text { 3-Briga na escola: entre } \\
\text { estudantes; hostilidade } \\
\text { entre gangues; roupas: } \\
\text { uniforme escolar }\end{array}$ & $\begin{array}{c}\text { Localização das } \\
\text { personagens femininas em } \\
\text { segundo plano, agressão de } \\
\text { homens; corpo mostra a } \\
\text { juventude em contraste } \\
\text { com a idade adulta; } \\
\text { mulheres sendo perseguidas } \\
\text { por homens; de lineamentos } \\
\text { definidos, traços leves; } \\
\text { característica dos traços da } \\
\text { face como sendo } \\
\text { ocidentais; beleza feminina; } \\
\text { dois rapazes; diferença } \\
\text { entre o visual comum do } \\
\text { estudante e o fantástico do } \\
\text { demônio; ambiente } \\
\text { fantasmagórico; ambiente } \\
\text { escolar, lugar } \\
\text { desorganizado como pano } \\
\text { de fundo, construção, } \\
\text { jovens brigando em } \\
\text { primeiro plano, atos de } \\
\text { violência em grupo com } \\
\text { jovens, valorizando os } \\
\text { corpos, esbeltos e } \\
\text { combalidos dos } \\
\text { agressores/agredidos. }\end{array}$ & $\begin{array}{c}\text { Juventude como algo } \\
\text { natural em quase todos os } \\
\text { personagens; personagens } \\
\text { mais velhos são professores } \\
\text { (homens) que são agredidos } \\
\text { por mulheres belas e } \\
\text { jovens; linchamento; } \\
\text { Escola e Castelo medieval } \\
\text { têm algo em comum: são } \\
\text { arena da violência; A } \\
\text { violência como forma de } \\
\text { manter a paz entre as } \\
\text { pessoas; A violência como } \\
\text { forma de resolver os } \\
\text { problemas entre os jovens; } \\
\text { Juventude como forma de } \\
\text { dinamicidade de vida: tudo } \\
\text { deve ser feito na juventude; } \\
\text { viver a vida intensamente; } \\
\text { estudos como algo } \\
\text { secundário; primazia pelo } \\
\text { gosto de aventura. Yusuke } \\
\text { é visto como o herói } \\
\text { bonachão, indisciplinado e } \\
\text { disposto a ajudar a todos. }\end{array}$ & $\begin{array}{l}\text { 1- Mostra a tendência à } \\
\text { autonomia, Disposição } \\
\text { feminina à luta contra } \\
\text { estruturas machistas e } \\
\text { paternalistas } \\
\text { (professores/escola), } \\
\text { sexualidade fica entre um } \\
\text { plano secundário e de } \\
\text { primazia: namoro juvenil, } \\
\text { sem um compromisso } \\
\text { definido; paixão juvenil; 2- } \\
\text { Luta entre o bem e o mal; } \\
\text { derrota do de mônio pelo } \\
\text { humano: o bem prevalece; } \\
\text { sangue é a forma de } \\
\text { expressar o dano, que a luta } \\
\text { foi dolorosa e não fácil; 3- } \\
\text { Amizade como forma de } \\
\text { suporte para as dificuldades } \\
\text { do dia-a-dia; briga entre } \\
\text { jovens é algo comum: } \\
\text { resolução de suas } \\
\text { diferenças. }\end{array}$ \\
\hline
\end{tabular}

No quadro 3, no nível denotativo, as ações tiveram que ser comprimidas em três momentos diversos por que as imagens, ao longo do texto, denotavam significados e significantes que só poderiam ser reunidos nestes espaços subjetivos.

No quadro 4, expõe-se o resultado da análise em Fushigi Yûgi n ${ }^{\circ} 36$ em que tanto a juventude como o corpo são elementos essenciais para a difusão da idéia de movimento e continuidade das ações.

Os dois quadros (números 3 e 4) têm vários elementos comuns. A violência, o corpo jovem, a amizade, o amor, a magia, os demôni- 
Qaudro 4 - Relatório de Análise da Edição nº 36 de Fushigi Yûgi

\begin{tabular}{|c|c|c|c|}
\hline Denotativo & Sintagma & Mito & Cultura \\
\hline $\begin{array}{l}\text { 1-Conversa entre seres } \\
\text { humanos e fantasmas, } \\
\text { pessoas que convivem entre } \\
\text { um mundo real e um } \\
\text { mundo contido em um livro } \\
\text { mágico, roupas de } \\
\text { adolescente } \\
\text { femininas/uniforme } \\
\text { escolar: saia, meias } \\
\text { soquete, colete, gravatinha; } \\
\text { cabelos longos e lisos, } \\
\text { loiros e negros; roupas } \\
\text { estilizadas da idade } \\
\text { medieval chinesa (por volta } \\
\text { do séculoX d.c); } 2 \text { - Amor } \\
\text { entre jovens de mundos } \\
\text { diferentes; apoio dos } \\
\text { amigos de ambos os } \\
\text { mundos: momentos ale gres } \\
\text { e de discórdia, valorização } \\
\text { do sentimento amor como } \\
\text { aquele que salva e liberta as } \\
\text { pessoas e as almas; 3- } \\
\text { Entidade maligna que } \\
\text { deseja destruir e conquistar } \\
\text { o mundo real e o mundo } \\
\text { mágico; 4- Luta entre os } \\
\text { demônios e os } \\
\text { humanos/fantasmas pela } \\
\text { liberdade e paz: sangue, } \\
\text { derrota do demônio e do } \\
\text { mal a meaçador; 5- futuro } \\
\text { de paz/amor e } \\
\text { solidariedade: pares } \\
\text { românticos terminam a } \\
\text { estória com um 'final feliz'. }\end{array}$ & $\begin{array}{l}\text { Personagens femininas em } \\
\text { segundo pla no, sendo } \\
\text { atacadas ou ajudando aos } \\
\text { personagens masculinos, } \\
\text { que são maioria. Sem } \\
\text { contraste no âmbito da } \\
\text { juventude, todos os } \\
\text { personagens são jovens } \\
\text { (valoriza essa faixa etária); } \\
\text { Mulheres de belo porte } \\
\text { (rosto com feições } \\
\text { ocidentais, corpo miúdo, } \\
\text { infantilizado); homens } \\
\text { belos, corajosos de alta } \\
\text { estatura, magros; demônio } \\
\text { (o mal) como sendo um } \\
\text { jovem de belas feições; } \\
\text { Cidade e mundo do além } \\
\text { como palco de lutas; cidade } \\
\text { real como plano } \\
\text { secundário; violência } \\
\text { contra a personagem } \\
\text { feminina principal; } \\
\text { personagem masculino } \\
\text { central como agressor e } \\
\text { vitima da agressão, plano } \\
\text { central, violência como } \\
\text { foco primaz das ações: } \\
\text { resistência do corpo jovem; } \\
\text { O corpo juvenil serve como } \\
\text { 'prancha' de apoio às cenas } \\
\text { violentas (suporte). }\end{array}$ & $\begin{array}{l}\text { Juventude é foco dos } \\
\text { desejos: de amor e de } \\
\text { poder. Ingenuidade } \\
\text { feminina; Inveja feminina: } \\
\text { disputa entre duas mulheres } \\
\text { por um mesmo homem. } \\
\text { Mundo medieval como } \\
\text { algo antes inalcançável e } \\
\text { próximo por causa da } \\
\text { magia; Magia como fonte } \\
\text { de todos os poderes. Amor } \\
\text { como sendo uma espécie de } \\
\text { magia; Amor como sendo } \\
\text { uma forma de arma } \\
\text { (defesa/ataque); Amor e } \\
\text { violência se misturam e } \\
\text { parecem faces diferentes de } \\
\text { uma mesma 'moeda'; } \\
\text { Juventude e amor são quase } \\
\text { que sinônimos; Amor e } \\
\text { maldade não condizem: } \\
\text { final trágico, morte, } \\
\text { desgosto, sem salvação à } \\
\text { curto prazo, almas } \\
\text { angustiadas; Fantasmas } \\
\text { querem sobrepujar os } \\
\text { deuses: divindades jovens, } \\
\text { belas e poderosas. }\end{array}$ & $\begin{array}{l}\text { 1- Tendência à valorização } \\
\text { da bele za feminina e } \\
\text { masculina, depreciação do } \\
\text { que é velho; 2- Amor } \\
\text { transcende ao tempo e } \\
\text { resiste às tentações, o amor } \\
\text { tudo resolve; 3- Mal é belo } \\
\text { e sedutor, tenta destruir e } \\
\text { conquistar, separar, usa } \\
\text { mentiras; 4- luta entre o } \\
\text { bem (humanos) e o mal } \\
\text { (demônios) o bem } \\
\text { prevalece, com perdas e } \\
\text { danos: sangue como mostra } \\
\text { da dor, do que é perdido; 5- } \\
\text { o futuro de paz e amor pode } \\
\text { ser alcançado com luta. } \\
\text { Amizade é um sentimento } \\
\text { valorizado pois une até os } \\
\text { opostos (mundo real e } \\
\text { mundo do além). }\end{array}$ \\
\hline
\end{tabular}

os, o mundo do além e o mundo real estão entrelaçados. As brigas são constantes, e os jovens estudantes são o foco principal. As disputas podem tanto ser em um mundo irreal, ou na escola. Muitas vezes existem relações pessoais entre aqueles personagens que são agredidos e aqueles que são agressores.

No aspecto denotativo, os jovens sempre são colegiais que não têm uma boa relação com os estudos, não tendo um lugar definido no mundo real, pois não se enquadram na estrutura comum dada aos jovens que é a vida estudantil. Uma vez retirados deste espaço, eles ficam 'soltos' para a continuidade de ações fantásticas que se seguem. Mesmo que as relações com a escola sejam mantidas e as personagens principais continuem a frequientá-la, as estruturas de ensino mantêm um status secundário, onde apenas seu espaço físico será importante, colocado como a arena de lutas entre estudantes contra demônios.

Para dar maior ênfase ao fantástico, recorre-se ao aspecto mítico da criação de divindades e, mais ainda, de demônios ('youkais' no idioma japonês). Somente o corpo jovem tem condição de suportar tamanha experiência que é, ao mesmo tempo, estudar, amar, lutar e sofrer. Como maiores obstáculos, o jovem deve enfrentar uma verdadeira horda de seres poderosos e encontrar dentro de si também um po- 
der que ele não sabia possuir. O lendário mal é realçado na figura destes seres mitológicos, seja da antiga China ou do Japão. Porém, a figura esconde o sentido da outra face de si. Nada mais são do que um outro lado do próprio ser humano, aquele que faz maldades e deve ser controlado.

O corpo feminino é violentado na medida em que já começa a participação de maneira secundária, quase não aparecendo. Depois se constitui como a personagem que deve ajudar ao Homem nas vitórias frente ao mal. A feminilidade é lembrada de forma infantilizada, desde o próprio corpo até como algo que deve ser controlado por ser fútil e sem valor. Beleza e disputa por uma personagem masculina são a tônica do ser feminino nestas histórias gráficas.

Apesar disto, as bishoujo ('belas garotas' no idioma japonês) mostram a que vieram quando estão com a responsabilidade de salvar o mundo. É essa feminilidade que norteia o 'fazer correto' para que a derrota não ocorra. Outra vez subentende-se o aspecto do 'controle social', pois a mulher sempre tem que fazer a coisa certa para não ser mortificada. Já as personagens masculinas terão em seus corpos as marcas das batalhas, principalmente os famosos hematomas e o sangue escorrendo em profusão dos ferimentos.

A transição entre os dois mundos é necessária porque mostra as formas de estilização do 'fugir deste mundo'. O mundo real é encarado como algo enfadonho, entediante. Para encerrar tal sequiência, algo extraordinário deve acontecer. Então, a supressão da realidade em prol do irreal e impossível se faz presente como uma ruptura do normal e estático. A subversão desta ordem é necessária para que a história gráfica não mingüe. Alguns autores mantêm uma 'distância estética', que é a técnica de enfeitar demasiadamente a estória para que o leitor não se perca na fantasia apresentada, mantendo uma linha segura com a sua própria realidade. Muitos leitores-fãs assumem uma postura de aden- trar profundamente na estória contada, paralisando sua vida, o que é um dissabor para os editores.

Os sentimentos de amor e amizade são vistos como armas porque assim os heróis podem se defender, como um grupo coeso contra as forças do mal. Então, segundo FresnaultDeruelle $^{27}$ :

"Os personagens de H.Q. existem apenas para viverem intensamente. Este é, com efeito, o destino deles, pois só aparecem em função do recorte seletivo de um cartoonist decidido a pôr em cena apenas os momentos que importem. As relações interpessoais, reduzidas ao essencial, às vezes mesmo exacerbadas, tecem assim um microespaço, específico das H.Q." (p.125).

Tais sentimentos servem de significado para todas as ações que possam existir no minguado espaço que há nos enquadramentos; dessa forma, o leitor consegue entender de maneira mais clara tantas seqüências de condutas e intenções que ocorrem quase que sempre de maneira rápida entre as personagens. $\mathrm{O}$ sentido que os sentimentos dão às histórias gráficas preenche os vazios entre os enquadramentos e estimula o leitor a identificar origens e objetivos, como se fossem um vetor. No caso destes dois mangás, amor e amizade andam juntos à violência. Luta-se por um amor correspondido, por outro não-correspondido, por uma antiga amizade e por uma nova também, afinal, brigase por qualquer motivo, desde a salvação do mundo, até a escolha entre dois amores. Diferentemente dos comics, os mangás expõem a sexualidade das personagens, desde o sexo, do namoro ao incesto. Mesmo que a temática não seja central, podem-se encontrar resíduos dessa sensualidade.

Portanto, a violência permeia o contexto dos enquadramentos. Como diz Fresnault-Deruelle ${ }^{27}$ : "A violência - é um fato - mora nas H.Q. Sem querer reduzir a abordagem do espaço pessoal tátil à manifestação da violência, 
é evidente que ela ocupa lugar central (...)".(p.137). Embora a mesma não seja a maior quantidade do conteúdo.

\section{CONCLUSÃO}

Conforme Vergueiro ${ }^{25}$, para a intelectualidade brasileira os estudos com histórias gráficas ('histórias em quadrinhos') seriam uma forma secundária de construção de conhecimento, atribuindo-lhes uma conotação de infantilidade. Contudo, o formato de pesquisa documental, junto à análise semiológica, revelou ser muito útil para a exploração dos enquadramentos e desvelamento dos sentidos ocultos. Um exemplo é a tradução dos títulos de ambos os materiais, 'O Jogo Misterioso' e 'Brincando com Espíritos', que, em seu conteúdo, nada têm de brincadeira visto que as ações e intenções trazem nas imagens: amor, traição, violência, amizade, paixão, indisciplina etc.

No que diz respeito às hipóteses aventadas, a hipótese de que os personagens masculinos são fonte mais freqüente de violência do que os femininos foi comprovada, porém a de que haveria um acréscimo na violência expressa a cada edição não foi alcançada. Em Yu Yu Hakushô, a edição $n^{\circ} 10$ foi onde houve mais violência; em Fushigi Yûgi, embora a última pu- blicação tenha sido a mais violenta, outros números anteriores tiveram exposição de bastante violência, precedidos por outros com menor violência ( $\mathrm{n}^{\circ} 18,19$ e 20$)$, ocorrendo uma oscilação nesta frequiência. Comprovando que a violência pode estar espalhada de forma não uniforme nestes materiais.

Para a cultura japonesa, esta mídia é importante como uma forma de manter os ideais de amizade e pacifismo que surgiram forçosamente depois da derrota do Estado Militar na década de 1940, uma espécie de transferência das intencionalidades violentas para a cultura de massa, muito mais simples de se administrar. Isso pode ser visto também na estética das personagens (olhos grandes e queixo fino), que nãoé típica das pessoas orientais e que pode significar a identificação e valorização do ocidental e a culpabilização para este 'outro' (estrangeiro) de algumas situações inadvertidas e pouco comuns à sociedade nipônica.

Por fim, faz-se necessário afirmar que a violência contida nos mangás é contextualizada e que não se pode afirmar que as ações desregradas de jovens tenham como causa esta mídia, mas que, por sua vez, também é necessária o regramento das tarjas indicando a faixa etária de acesso para este material, bem como confiar na capacidade de dar sentido, que crianças e adolescentes possuem, acerca da inverossimilhança que existe nestes conteúdos.

\begin{abstract}
Graphic stories (also known as comics) are one of the most ancient forms of expression of mankind. They reflect society values and can serve as a form of education. The research aims to recognize violence descriptors, stylized as aggressive imagery and intentionality of commiting a violent act in the characters of Fushigi Yûgi and Yu Yu Hakushô, which are graphic stories of japanese origin (also known as Manga). Statistical descriptive analysis linked to semiologic analysis was used as a procedure to recognize the main components which have been exposed. From some results it was discovered that these visual resources contain not only explicit violence, but also intentional violence, the first bein more pervasive, and that characters of the masculine gender are more aggressive than the ones of feminine gender. It can also be concluded that this stories should not be considered as the unique and most dangerous sources of violence in society.
\end{abstract}

Key words: Graphic stories. Mangas. Violence. 


\section{REFER $\hat{E} N C I A S$}

1. Cirne M. Heróis e personagens - talvez sim, talvez ficção. Estudos de Psicologia. 1997; 2 (1): 86-108.

2. Franco ES. HQtrônicas: do suporte papel à rede internet. São Paulo: AnnaBlume/Fapesp; 2004.

3. Yonezaka Y, Sakata S, Shimizu I, Torikai S-I, Ko matsu M. O culto mundial ao desenho animado japonês. Nipônia 2004; 27: 4-16.

4. Herói (2005). O que é mangá? www.heroi.com.br (consultado em 17 de Abril de 2005).

5. Bosi E. Cultura de massa e cultura popular. Petró polis: Vozes; 2000.

6. Nagado A. O mangá no contexto da cultura pop japonesa e universal. In: Luyten SB. Cultura pop japonesa: mangá e animê. São Paulo: Hedra; 2005. p.49-57.

7. Almeida LF. Espelhos míticos da cultura: cinema, TV e quadrinhos na Índia. São Paulo: AnnaBlu me; 1999.

8. Nascimento NM, Melo, VRP. .A influência das mídias na formação social artística e cultural das crianças e adolescentes. In: Simpósio Nacional de Geometria Descritiva e Desenho Técnico, 16. Santa Cruz do Sul; 2003. p.8.

9. Wilson BJ, Kunkel D, Linz D, Potter, WJ, Don nerstein E, Smith SL, Blumenthal E, Berry M, Federman J. A natureza e o contexto da violên cia na televisão americana. In: Carlson U, Von Feilitzen C. A criança e a violência na mídia. Brasília: Unesco/Ed. Cortez; 1999. p.71-91.

10. Alves JM. Histórias em quadrinhos e educação infantil. Psicologia: Ciência e Profissão 2001; 21(3): 2-9.

11. Moliné A. O grande livro dos mangás. São Paulo: Editora JBC; 2004.

12. Tazawa Y, Matsubara S, Okuda S, Nagahata Y. História cultural do Japão - Uma perspectiva. Bra sília: Ministério dos Negócios Estrangeiros do Japão;1973/1985.

13. Luyten SB. Mangá.: o poder dos quadrinhos ja poneses. São Paulo: Ed. Hedra; 2000.

14. Luyten SB. O tripé japonês. Bravo, 2004; 86 (8): 51-3.

15. Awano E. Mangá brasileiro. In: .In: Luyten SB. Cultura pop japonesa: mangá e animê. São Paulo: Hedra; 2005. p.95-100.

16. Oka AM. Mangás traduzidos no Brasil. In: Luyten SB. Cultura pop japonesa: mangá e animê. São Paulo: Hedra; 2005. p.85-94.

17. Bolognini CZ, Payer MO. Línguas de imigrantes. Ciência e Cultura 2005; 57(2):42-6.

18. Times (2004). Drawing in the gals. Move over, guys, graphics for girls are the hot new in Japa nese comics. www.times.com (consultado em 28 de fevereiro de 2004)

19. Barthès R. Mitologias. Rio de Janeiro: Bertrand do Brasil; 1957/1993.

20. Penn G. Análise semiótica de imagens paradas. In: Bauer M, Gaskell G., (orgs.) Pesquisa qualita tiva com texto, imagem e som: um manual prático. Petrópolis: Vozes; 2003.

21. Fiorin JL Linguagem e ideologia. São Paulo: Áti ca; 1990.

22. Barthès R. Elementos de semiologia. São Paulo: Cultrix; 1971.

23. De Souza ML, Gomes WB. Evidência e interpre tação em pesquisa: as relações entre qualidades e quantidades. Psicologia em Estudo 2003; 8(2): 83-92.

24. Flick U. Uma introdução à pesquisa qualitativa. Porto Alegre: Bookman; 2004.

25. Vergueiro W. A pesquisa em quadrinhos no Bra sil: a contribuição da universidade. In: Luyten SB. Cultura pop japonesa: mangá e animê. São Paulo: Hedra; 2005. p.15-26.

26. Couto, WGS, Menandro, PRM. Imagens da ado lescência feminina na revista Capricho. Rev Bras Cresc Desenv Hum, 2003; 13 (1): 63-78.

27. Fresnault-Deruelle P. O espaço interpessoal nos comics. In: Hoble A. Semiologia da representa ção: teatro, televisão, história em quadrinho. São Paulo: Cultrix; 1980. p. 125-46. 